\title{
Attenuation of Toxic Power of Atractylis Gummifera
}

\author{
Siham Errai, Youssef khabbal, Mohamed Faid, Abdelwahed Maataoui,Mohammed Elmidaoui, \\ Mohamed Benbella, and Abdelfattah Abdellaoui
}

\begin{abstract}
Atractylis gummifera is a plant belonging to the Asteraceae family which is known for its toxicity, Despite this toxicity and fatal poisoning, the plant is still widely used in traditional medicine for therapeutic. In absence of a specific antidote likely to mitigate the toxicity of this plant, the search for factors that attenuate its toxic power is of extreme importance. In order to realize this study, we used the root of Atractylis gummifera which underwent so treatments, and were administered to rats by gavage. This allowed us to estimate the relevance of each technique in terms of exhaustion toxic substances or alleviation of toxicity by assessing the mortality rate caused by each type of extract. This attenuation was observed at high and moderate temperatures, and increased with increasing of incubation time. Acidification also enhances the efficiency of the attenuation of the toxicity at $\mathrm{pH}=2$
\end{abstract}

Keywords - Atractylis gummifera, toxicity, DL 50, attenuation

\section{INTRODUCTION}

Therapy plants, also known as herbal medicine, can prevent and even cure some disorders of the body naturally. This therapy however requires caution because of misuse of a plant may not result in the betterment but the disease. However, numerous cases of hepatic and renal injury and even death were associated with the use of herbal medicines [1]-[2] [3][4]. The safety of several commercially available herbs has recently come into question due to reports of adverse reactions with prescription drugs and the use of inappropriate dose which far exceeds the lethal dose. The safe and effective use of medicinal herbs has therefore been identified as a top research priority [5]-[6]- [7].

Atractylis gummifera L. is an acaulescent perennial medicinal herb with a long woody root up to $30-40 \mathrm{~cm}$ long and $7-8 \mathrm{~cm}$ diameter. It has deeply divided prickly long leaves in a rosette $30-70 \mathrm{~mm}$ wide; pink florets in $3-7 \mathrm{~cm}$ wide capitula with middle bracts with three long apical spines . It grows in Northern Africa and Southern Europe in moist soils of cultured grounds and waste places [8].

Atractylis gummifera is still widely used in traditional medicine for therapeutic purposes such as fumigation against

Errai Siham, Laboratory of Physiology, Pharmacology Health and Environment Unit of Bioremediation and Environment Department of Biology. Faculty of Sciences Dhar EL Mahraz, Université Sidi Mohamed Ben Abdellah, BP : 1796, Fès.Morroco

siham.errai1@usmba.ac.ma colds, dizziness and headache, infusion against bleeding during childbirth, anti-syphilis, gangrene, hemorrhoids, skin cancer, poultice dries, heal wounds, as well as against boils, as a purgative, emetic and worming [9].

Interestingly, the effectiveness of the remedy as an antiinflammatory and anticancer agent is supported by pharmacological studies [10]-[11].

According to the Poison Control Centre of Morocco (CAPM), The Atractylis gummifera ranks first plants responsible for poisoning, of 487 cases reported between 1980 and 2013 [12]. Year Among patients for whom the CAPM has data on evolution, $53.8 \%$ died, of which $62.2 \%$ are children under ten years. According to the reported data, $77.5 \%$ of deaths are attributed to accidental poisoning. Noteworthy that there is an average of ten cases of intoxication and 4.1 deaths per year (Fig.1).
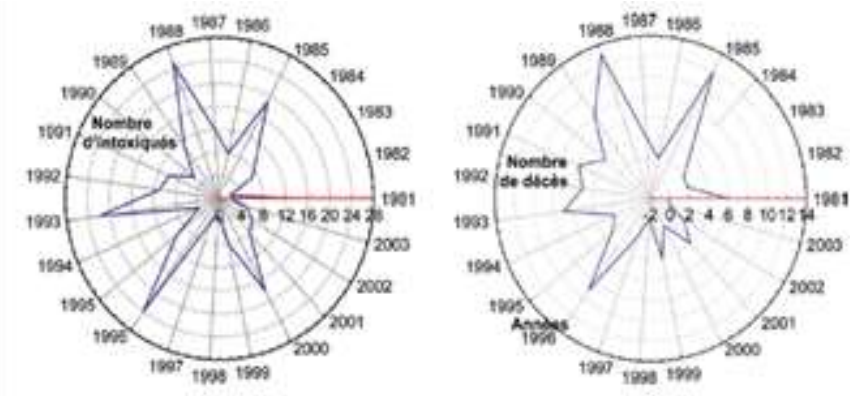

Fig. 1: number of reported poisoning victims and deaths (Poison Control Center of Morocco., 2013)

However, the toxicity of Atractylis gummifera is due to the presence of two toxic diterpenoid glucosides: atractyloside(ATR) and carboxyatractyloside (CATR).

The toxicity and chemical profiles of ATRs are highly dependent on the variations in both species and processing [13]-[14].Interest in these compounds was stimulated by the high toxicity of the sulphated glucoside and aglycone, which has been responsible for many deadly poisonings [15]-[16]. 4carboxyatractyloside (CATR), which is more toxic than ATR, is found in fresh, but not dried plants because it is decarboxylated to ATR during ageing or desiccation [13][16].

The structures of ATR and its analogue CATR are illustrated in Figure 2. The effect of $\mathrm{pH}$ and temperature on the ATR has been the subject of several previous works related to medicinal herbs, except Atractylis gummefera [17]-[18]. 


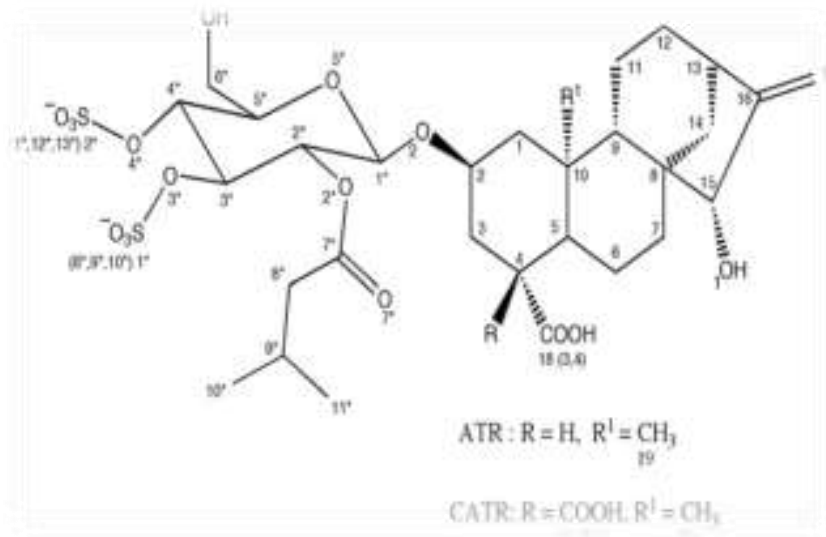

Fig.2: Atomic numbering of ATR and CATR (Jean-F S, and al 2012)

Furthermore, there is no report to our knowledge on the effect of the of $\mathrm{pH}$, temperature, leaching and conservation on the degradation of the toxicity of Atactylis gummifera known for its high (ATR and CATR) contents.

The objective of this study being to find a method which will allow mitigating or degrading the toxicity of Atractylis gummifera extract via Hydro-processing, $\mathrm{PH}$, Temperature and conservation providing the results that can help assess the safety and risks (LD50) of medicinal herbs in the pharmaceutical industry and ethnopharmacology.

\section{II.MATERIALS AND METHODS}

\section{A. Plant material}

Fresh Atractylis gummifera roots used in the present study were collected in Moulay yakoub, Fez on Mai 2014 in Morocco. The plant of Atractylis gummifera L was identified by $\operatorname{Pr}$ BARI A, and $\operatorname{Pr}$ MEZIANE D. botanists at the Department of Biology, Faculty of Science (Fez). Roots of this plant were then cleaned, separated in two lots. One of the lot was called Lot1 was stored in the refrigerator at a temperature of 4 to $6^{\circ} \mathrm{C}$ ). The second lot labelled lot 2 was let dry under shade at the Laboratory of Biological Department, University of Dhar El Mehraz Fez for four weeks.

\section{B. Dilution of aqueous extracts of fresh and dried root of} Atractylis gummifera

The purpose of this technique was to study the impact of six successive dilutions on toxicity of Atractylis gummifera root extract (TABLE I). A sample of the $100 \mathrm{~g}$ of Atractylis root named lot1, was prepared by cutting very small and thin slices of root. The root sample was immersed in $200 \mathrm{ml}$ of distilled water. The mixture was allowed to break down for 4 hours in a shaker bath at room temperature $\left(20^{\circ} \mathrm{C}\right)$. The water root extract was obtained by filtering the reset of the root sample in an Erlenmeyer flask. The concentration of the root aqueous extract was $0.5 \mathrm{~g} / \mathrm{mL}$. Taking in consideration the average rat body weight $(\mathrm{BW})$ of Westers which is around $250 \mathrm{~g}$, the concentrations of aqueous extract of root of Atractylosis gummeifera tested appeared in table 1.
TABLE I: CONCENTRATION OF AqueOUS EXTRACT OF Fresh RoOT OF ATRACTYLOSIS GUMMIFERA (G.KG BW-1) TESTED IN THE EXPERIMENT

\begin{tabular}{|c|c|c|c|c|c|}
\hline $\begin{array}{c}\text { Weight (g) of } \\
\text { root extract } \\
\text { per Kg of BW } \\
\text { of rat }\end{array}$ & $\begin{array}{c}\mathbf{1 0 g} / \mathbf{K g B} \\
\mathbf{W}\end{array}$ & $\begin{array}{c}\mathbf{5 g} / \mathbf{K g} \\
\mathbf{B W}\end{array}$ & $\begin{array}{c}\mathbf{1 g} / \mathbf{K g} \\
\mathbf{B W}\end{array}$ & $\begin{array}{c}\mathbf{0 , 1 g} / \mathbf{K g} \\
\mathbf{B W}\end{array}$ & $\begin{array}{c}\mathbf{0 , 0 1 g} / \mathbf{K g} \\
\mathbf{B W}\end{array}$ \\
\hline $\begin{array}{c}\text { Volume of } \\
\text { aqueous } \\
\text { Extract of root } \\
\text { (mg/L) per } \\
\left.\text { (g.Kg BW } \mathbf{~}^{-1}\right)\end{array}$ & 0,5 & 0,25 & 0,05 & 0,005 & 0,0005 \\
\hline $\begin{array}{c}\text { Volume of } \\
\text { root aqueous } \\
\text { extract } \\
\text { ingested per } \\
\text { rat }\end{array}$ & $5 \mathrm{ml}$ & $5 \mathrm{ml}$ & $5 \mathrm{ml}$ & $5 \mathrm{ml}$ & $5 \mathrm{ml}$ \\
\hline
\end{tabular}

\section{Preparation of aqueous extract of dried root}

The same experiment was conducted using the same conditions for the root sample of dried root under shade. Dilutions tested are presented in table 1

\section{Technical exhaustion}

The first aqueous extract of a sample of $100 \mathrm{~g}$ fresh root named E1 was obtained by using the same procedure as in the 2.1.1 experiment above. The aqueous extract E1 was then filtered in an Erlenmeyer. The remainder of E1 after its filtration was diluted a second time and filtered under E1 conditions to obtain aqueous extract E2. The cake of E2 was recovered, diluted and filtered using the same procedure as for E1 and E2 to obtain the last aqueous extract. which is the extract.

The preparation of aqueous extracts (E'1, E'2 and E'3) of dried roots of Atractylis gummifera was based on the procedures used in the experiments 2.1.1 and in 2.1.2 for fresh root.

E. Toxicity of root extracts under differing temperatures and exposure durations.

A thirty new aqueous extracts were prepared. Eighteen for dried sample root and eighteen for fresh sample root.

Preparation conditions and procedures followed were identical to those described for the dilution effect in sections B. These extracts were used to test the effect of five temperatures

levels $\left(20,40,60,80\right.$, and $\left.100^{\circ} \mathrm{C}\right)$ combined to three durations (30, 60 and 120mn) on Atractylosis gummifera root aqueous extract toxicity.

\section{F. Effect of pH on toxicity of the extract.}

Four samples of $100 \mathrm{~g}$ of dried root of Atractylis gummifera were immersed in a $200 \mathrm{ml}$ of distilled water and let to decay under $20^{\circ} \mathrm{C}$ during four hours. The residue of the four samples was successively filtrated in an Erlenmeyer. The $\mathrm{pH}$ of each filtered sample was recorded $(\mathrm{pH}=5.8)$ and the filtrate was stored until use. Knowing the $\mathrm{pH}$ of the four samples was 5.8. One of the four samples was randomly selected and considered as $\mathrm{pH} 1$. The $\mathrm{pH}$ of the remaining samples was adjusted by adding either $\mathrm{H} 2 \mathrm{SO} 4$ or $\mathrm{NaOH}$ to obtain the $\mathrm{pH} 2=2$ for the 
second sample, The $\mathrm{pH} 3=10$ for the third sample and à The $\mathrm{pH} 4=12$ for the fourth sample.

\section{G. Assays on rats}

Male Westar rats with an average weight of $250 \mathrm{~g}$ were used for this study. Animals were checked for abnormality and any other disease symptoms. The animals were bred and housed in the animal house.

The rats were randomly divided into lots of 12 rats each which were kept in the animal house at ambient temperature around $25^{\circ} \mathrm{C}$, with a photoperiod of $12 \mathrm{hlight} / 12 \mathrm{hdark}$ and a free access to a standard pellet feed and tap water ad libitum. Animals were acclimatized for at least one week before using them in our experiments. The animals were exposed only once to every experiment.

Prior to the assays, animals were subjected to a fasting period of 24 hours. Extracts doses to be tested for their toxicity were administered by force-feeding with a special probe; the research was conducted in accordance to the ethical rules on animal experimentation. Animal lots were examined for mortalities and abnormal behaviour after 24 hours. DL50 were defined as the lowest concentration that had killed $50 \%$ of Westar rats.

\section{H. Toxicity of diluted aqueous of fresh root of Atractylis} gummifera.

A lot of six male Westars were randomly affected to each aqueous extract of the six dilutions presented in table 1 section 2.1.1. Westars of each group assigned to a dilution of aqueous root extract were individually feed by $5 \mathrm{ml}$ of this extract. Fourteen eight hours after feeding, the number of dead and alive Westars was counted.

The same procedure was followed in testing toxicity of the dry extract.

I.Toxicité of root extracts under differing temperatures and exposure durations

A lot of six Westar was randomly affected to each combination (temperature)x(treatment time). Westar were individually feed with $5 \mathrm{ml}$ of the extract. Fourteen eight hours after feeding the number of dead and alive rats were counted for each combination.

\section{J. Effect of four levels of $\mathrm{pH}$ of the aqueous root extract} on its toxicity.

A $5 \mathrm{ml}$ of each root filtrate was administered orally per Westar and repeated to get an effective of six Westar for a given $\mathrm{pH}$. The number of dead or alive Westars was counted $48 \mathrm{~h}$ after the treatment for each lot of rats and each $\mathrm{pH}$ level.

The procedure described above for dry root sample was followed for fresh sample to test the impact of the $\mathrm{pH}$ of the aqueous solution on Westar.

\section{K. Statistical Analysis}

All data were subjected to analysis of variance at 5\% significance level.The statistical analyses were performed using the program SPSS (Version 17.0).

\section{RESULTS}

\section{A. Toxicity of diluted aqueous extracts of Fresh and dried} roots of Atractylis gummifera

Oral administration to rats of 6 different doses of aqueous extracts of fresh and dried root of Atractylis gummifera, has led to a change in physical activity and behavior of the tested rats. They showed a reduction in their movement and a generalized shaking of their bodies. No significant difference between the doses of aqueous extracts of fresh or dried root on the percentage of Westers death was revealed by statistical analysis of the results. However, when aqueous extracts of fresh root and aqueous extract of dried root were analyzed apart, four dose groups were identified for each root form (fresh or dried) as shown in Figure 3: 10g / $\mathrm{kg}$ (rat body weight $=\mathrm{BW})>5 \mathrm{~g} / \mathrm{kgBW}>1 \mathrm{~g} / \mathrm{kgBW}>0.1 \mathrm{~g} / \mathrm{kgBW}=0.01 \mathrm{~g} /$ $\mathrm{kgBW}=$ Control.

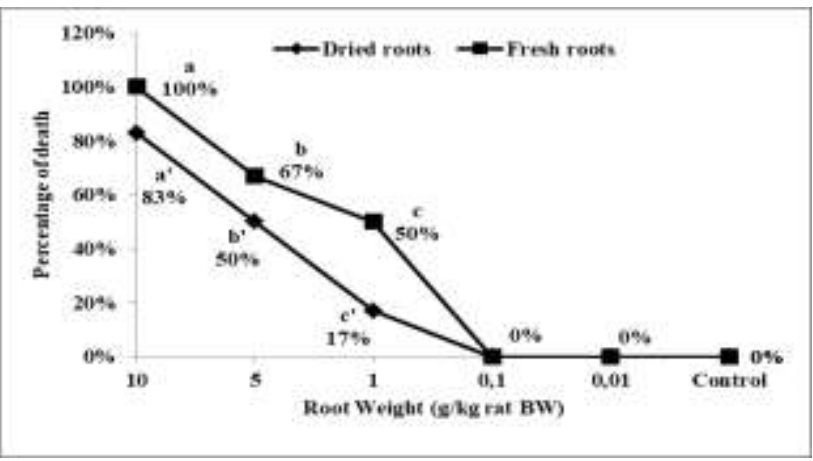

Fig. 3 Effect of five dilution levels on toxicity of aqueous water fresh root extracts of Atractylis gummifera .

*Values followed by the same letter were not significantly different at $\mathrm{p}=0,05$ according to $\mathrm{N}-\mathrm{S}-\mathrm{K}$ test;

Furthermore, the dilution of the aqueous extracts of fresh or dried roots induced a reduction of the effect of the toxicity of the aqueous extracts on rats. The reduction appears to be more pronounced in the case of the dried root aqueous extract for which the mortality percentage ranged from $100 \%$ recorded at the concentration of $10 \mathrm{~g} / \mathrm{kg} \mathrm{BW}$ to $17 \%$ at the dose of $1 \mathrm{~g} /$ $\mathrm{kg} \mathrm{BW}$. On the other hand, the aqueous extract of the fresh root showed a higher death rate: $100 \%, 67 \%, 50 \%$ and $0 \%$ respectively for $10,5,0.1$ and $0.01 \mathrm{~g} / \mathrm{kg} \mathrm{BW}$.

The results showed clearly that beyond an intake of $0.01 \mathrm{~g} /$ $\mathrm{kg} \mathrm{BW}$, the rate of mortality became important for the root aqueous extract of the fresh root as well as for the aqueous extract of the dried root (Fig. 3). The LD50 is thus reached at a concentration of $1 \mathrm{~g} / \mathrm{kg} \mathrm{BW}$ of the aqueous extract of fresh root and only at a concentration of $5 \mathrm{~g} / \mathrm{kg} \mathrm{BW}$ of dried root, which equals an LD50 dose 5 times lower than the one of the fresh dried root aqueous extract. These rates decline as well as the reduction of the concentration of the solution of the aqueous extract to cancel below 1g/kg BW (Fig. 3).

\section{B. Exhaustion effect on toxicity of fresh and dried root} aqueous extracts

The results of the experiment showed that for the first 
extraction (E1 and E'1), the mortality rate of Westars was the highest for the water extract of the fresh root (rate $=100 \%)$ and high for the aqueous extract of dried root (rate $=83 \%)$. In addition, the percentage of dead rats decreased as the number of extraction performed on the initial sample increased (Fig. 4). Moreover, the results also showed that the drying of the root alone brought down the Westars mortality by $27 \%$. The percentage of mortality among the other treatments were $33 \%$ (E2) and $17 \%$ (E3) for Westars batches nourished with the aqueous extract of the fresh root and 17\% (E'2) to $0 \%$ (E'3) for Westars lots feed with aqueous extracts of dried root (Fig. $3)$.

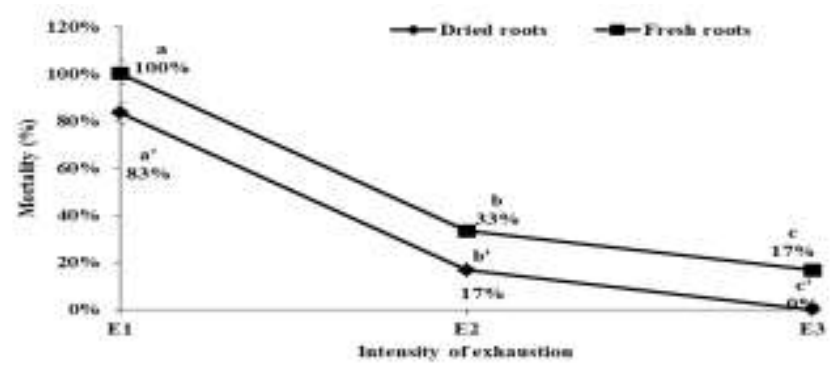

Fig. 4: The decrease of mortality level as the exhaustion treatment increased for fresh root (E1, E2, E3) and dried root (E1', E2', E3') of Atractylis gummifera.

*Values followed by the same letter were not significantly different at $\mathrm{p}=0,05$ according to $\mathrm{N}-\mathrm{S}-\mathrm{K}$ test;

It turns out that the first aqueous extraction of the fresh root E1 and of the dried root E'1 reduced considerably the content of toxic substances (ATR and CATR) in the aqueous extract of root of Atractylis gummifera. The batches of rats feed with the first two aqueous (E1, E'1) showed the highest mortality rates for E1 (100\%) and the high lethality rate for E'1 (83\%). The mortality rates in the second (E2) and third depletion (E3), were relatively smaller. They went from $33 \%$ to $17 \%$ and $17 \%$ to $0 \%$ for batches supplied with the extracts from fresh or dried roots respectively (Figure 4) these finding showed also that four weeks of drying under shade caused a significant and important decrease in rats' death. These results allowed us to conclude that longer drying would probably further reduced the toxicity of the aqueous extract.

\section{Effect temperatures and exposure durations on Toxicity of water root extracts}

The analysis of variance revealed a significant effect of temperature and duration of exposure of the aqueous extract of fresh root of Atractylis gummifera on its toxicity. The response of Westars rats to toxicity of the aqueous extract was used to assess the impact of treatment on the attenuation of toxicity. An increase of the temperature of the aqueous extract of the fresh root from $20^{\circ} \mathrm{C}$ to $100^{\circ} \mathrm{C}$, the rates of mortality deceased steeply. The highest percentage of rats death $(100 \%)$, were observed when the aqueous extract was subjected to temperatures ranging from $20^{\circ} \mathrm{C}$ to $80^{\circ} \mathrm{C}$ for fixed periods (Fig. 5).

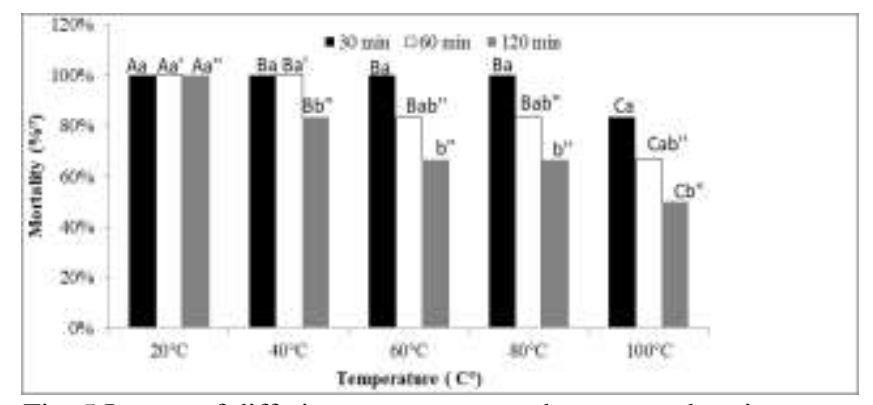

Fig. 5 Impact of differing temperature and exposure duration on toxicity of aqueous extract of fresh root of Atractylis gummifera *Values followed by the same letter were not significantly different at $\mathrm{p}=0,05$ according to $\mathrm{N}-\mathrm{S}-\mathrm{K}$ test;

By subjecting the aqueous extract of the fresh root of Atractylis gummifera to five temperatures $\left(20\right.$ to $200^{\circ} \mathrm{C}$ in steps of $20^{\circ} \mathrm{C}$ ) for $60 \mathrm{mn}$, the rate of Westars deaths decreases from $83 \%$ to $67 \%$ at $100{ }^{\circ} \mathrm{C}$ and from $100 \%$ to $83 \%$ for both $80^{\circ} \mathrm{C}$ and $60^{\circ} \mathrm{C}$ (Fig. 5). Samples of aqueous extract of the fresh root having undergone five temperatures $\left(20^{\circ} \mathrm{C}\right.$ to $100^{\circ} \mathrm{C}$ by increment of $20^{\circ} \mathrm{C}$ for $120 \mathrm{mn}$ were used to feed the Westers. The mortality rates ranged from $50 \%$ at $100{ }^{\circ} \mathrm{C}$ to $100 \%$ at $20^{\circ} \mathrm{C}$. The mortality rate reached $83 \%$ at $40^{\circ} \mathrm{C}$. The percentage of dead rats was equal for temperatures $60^{\circ} \mathrm{C}$ and $80^{\circ} \mathrm{C}$ (Fig. 5). These results would suggest that heat treatment of aqueous water extract from of the fresh root at $100^{\circ} \mathrm{C}$ for 4 hours would probably reduce the concentration of active substances below the LD50.

\section{D. $p H$ change}

For more characterization of the crude active principle of Atractylis gummifera, different $\mathrm{pH}$ were applied to the extract. The range of the $\mathrm{pH}$ studied concerned acidic and basic $\mathrm{pH}$ values ranging from $\mathrm{pH} 2$ to $\mathrm{pH} 12$. Results in figure 6 show effect of the $\mathrm{pH}=2$ on the active principle in the plant, so no mortality was observed in rats force-fed by the extracts at different $\mathrm{pH}>2$. This may demonstrate a high acido-basic stability to the active principle. These physico-chemical properties may help determining the high risk of the plant toxicity being resistant to many factors including temperature, extraction and $\mathrm{pH}$ (fig 6).

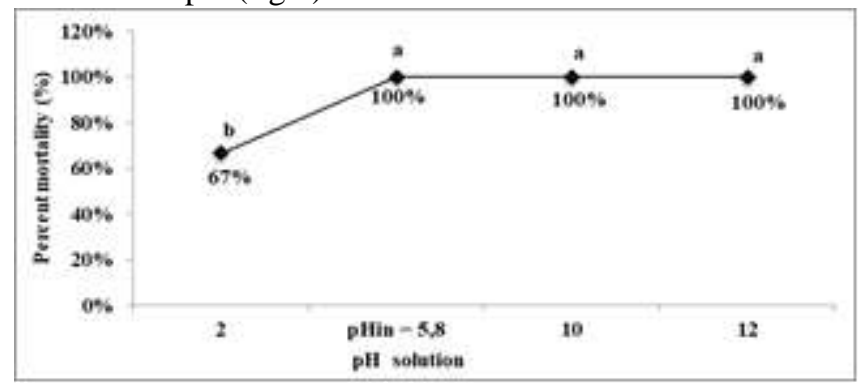

Fig. 6 Effect of the $\mathrm{pH}$ of the aqueous extract solution of Atractylis gummifera root on its toxicity

*Values followed by the same letter were not significantly different at $\mathrm{p}=0,05$ according to $\mathrm{N}-\mathrm{S}-\mathrm{K}$ test; 


\section{DISCUSSION}

Results of the first experiment showed that the toxicity of aqueous extract of root of Atractylis gummifera used to feed Westears varied depending on whether we use fresh or dried root. Indeed LD50 of aqueous extract of fresh root had toxicity 5 times higher than that of dried root. Similar results were reported by Liang-Yu Chen and chen L [17]-[18].on Atractylis gummifera. They suggested to store harvested samples for a long period before use. They didn't specify the duration of the storage period before use [19]-[20]. Our results showed that a drying period of the root of Atractylis gummifera for weeks under shade resulted in a significant decrease of aqueous extract toxicity. Diluted dried root aqueous extract induced higher decrease of death rates for four treatments out of five (Fig 3).

These results might mean that a longer drying period might be a way of decreasing the concentration of toxic compound and hence it's the lethacy risk. In a study conducted by chien $\mathrm{H}$ [21].the author reported that Atractyloside content of Atractylis gummifera root collected from 6 sites in Algeria varied among sites. From $0,10 \%$ to $0,27 \%$.In addition, Fassina G, Veronese G. in [22], reported that content of atractylode in roots of Atractylis varied in time and it content in leaves in shoots were high in winter and spring seasons. Romeuf et al (2006) reported for several periods of sampling an average content of heterosides not exceeding 0,2\%. In addition, Aqueous solution of Atractylis gummifera is composed of two molecules with different levels of toxicity.

This toxicity seemed to be higher for ACTR than ATR. However, ACTR possesses the characterictic of beeing hydrosoluble [23]-[24]-[25] and therefore its toxicity level tends to decrease under the effect of the dilution of the aqueous extract of the roots, both fresh and dry. Indeed, for this reason results accomplished in this study showed a significant and declining toxicity effect of aqueous extract of fresh and dried root of Atractylis gummifera as the number exhaussions increased $(E 1>E 2=E 3)$. On the other hand the toxiciy decrease of aqueous solutions of fresh and dried root of Actractylis gummifera on Westars was also provoked by the acidity of aqueous extract especially if the $\mathrm{pH}$ was maintained et $\mathrm{pH}=2$, value at which the death rate of westars was $67 \%$. On the contrary higher acidic $\mathrm{pH}$ such as 5.8 resulted in death $100 \%$ of Westers like $\mathrm{pH}=10$ and $\mathrm{pH}=12$.

The degradation of ATR by hydrothermal treatments as is shown in Figure 5. At high and moderate temperatures, degradation of ATR was observed and increased with incubation time. Acidification also enhances the efficiency of degradation $33 \%$ at $\mathrm{pH}=2$ and approximately $50 \%$ of ATR could be removed by hydrothermal processing at $100^{\circ} \mathrm{C}$ for 2 hours ( Fig.5) This is consistent with the results reported by [26]-[27]. Thereby, temperature effect on toxicity of aqueous of root extract remains dependent on duration of exposition. Results showed that the higher de duration of exposition of aqueous root extract to temperature the lower the rate of Westers. The LD50 was recorded at $100^{\circ} \mathrm{C}$ only when the duration of exposition of aqueous extract was $120 \mathrm{mn}$. This result suggests that doubling the exposition time at this temperature might probably result in a more degradation of toxic compounds and hence to a decrease of aqueous extract toxicity Solution [27]-[28]-[29]-[30]. This suggestion is supported by results of the experiemt where fresh and dried root were compared. In these case results showed for all experiments the a 4 week drying under reduced substantially the toxicity of the aqueous extract. The study of toxicity of aqueous extract of Atractylis gummifera roots showed that lethal doses of aqueous extract LD50 was $1000 \mathrm{mg} / \mathrm{kg}$ BW for fresh root and $5000 \mathrm{mg} / \mathrm{KgBW}$ for dried root. According to Hodge and Sterner [31]. Toxicity scale of Aqueous extract of Atractylis gummifera are very toxic as illustrated by the dilutions experiment (TABLE II).

TABLE II HODGE AND STERNER (2005) TOXICITY CLASSES

\begin{tabular}{|c|l|l|}
\hline Toxicity rating & Commonly used terms & \multicolumn{1}{c|}{ LD50 } \\
\hline 1 & Extremely toxic & Less than $\mathrm{mg} / \mathrm{Kg}$ \\
\hline 2 & Highly toxic & $1-50 \mathrm{mg} / \mathrm{Kg}$ \\
\hline 3 & Moderately toxic & $50-500 \mathrm{mg} / \mathrm{Kg}$ \\
\hline 4 & Slightly toxic & $500-5000 \mathrm{~m} / \mathrm{Kg}$ \\
\hline 5 & Practically non toxic & $5000-50000 \mathrm{mg} / \mathrm{Kg}$ \\
\hline
\end{tabular}

Finally Results showed that lethal concentration for fresh root was $1 \mathrm{~g} / \mathrm{kg} \mathrm{BW}$ while that of dried root was $5 \mathrm{~g} / \mathrm{kg} \mathrm{BW}$.

\section{V.CONCLUSION}

A conclusion section is not required. Although a conclusion may review the main points of the paper, do not replicate the abstract as the conclusion. A conclusion might elaborate on the importance of the work or suggest applications and extensi The results of this work show that the attenuation of the root toxicity of Atractylis gummifera, before being used in pharmaceutical industry is possible. By choosing the right sampling site (wetland) at the right stage (avoiding summer and spring). Thus the harvested samples

Must be dried and kept for a good period to be rid of a large part of its toxicity by the hydro-thermal and acidifying process, or of its totality by exhaustion and leaching of the toxic substances (ATR, CATR) known by their water-soluble character. As recommending that:

- It will be necessary to try with other species, Knowing that toxicity is higher in dogs than in mice and rats, suggesting an even higher toxicity in humans.

- Study the interaction between these parameters (fresh root, dry root, site, stage, $\mathrm{T}^{\circ} \mathrm{C}, \mathrm{pH}$, exhaustion)

- Study the effectiveness of these methods on other plants that contain the same toxic substances.

- Study the impact of these methods on the attenuation of the root toxicity of Atractylis gummifera by another route of administration

- Try to develop effective antidotes against these poisons in case of poisoning in order to save human lives. 


\section{REFERENCES}

[1] D. Larrey., Faure, S., 2011.. Journal of hepatology.

[2] F. Stickel, Schuppan, D., 2007. 39, 293-304. doi:10.1016/j.dld.2006.11.004

[3] F. Stickel, E. Patsenker, and D. Schuppan. 2005. Herbal hepatotoxicity. J. Hepatol. 43: 901-910.

[4] C. Haller, Dyer, J., Ko, R., Olson, K., 2002.Western journal of medicine

[5] J.J. Burns, Zhao, L., Taylor, E.W., Spelman, K., 2010. Toxicology 278, 140-159. doi:10.1016/j.tox.2009.09.020

[6] H.M., Cheng.; Li, C.C.; Chen, C.Y.; Cheng, W.Y.; Yang, S.Z. J. Ethnopharmacol. 2010, 132, 429-437

[7] Fakchich J, Elachouri M ; Journal of Ethnopharmacology 154 (2014) 76-87

[8] J. Vallejoa, Perala D., Gemiob P., Journal of Ethnopharmacology 126 (2009) 366-370.

[9] J.M .Otero, 1983. Medicina popular en La Siberia. Alminar 44, 6.

[10] C., Gaudeau, Gouthiere,L.,1991.French Patent FR2658420-A1. http://www.patfr.com/ 199108/FR2658420.html.

[11] J. El-Hilaly , Mohamed H, Badi^aa L ; Journal of Ethnopharmacology 86 (2003) 149-158

[12] Poison Control Centre of Morocco

[13] D. Obatomi., Bach, P., 1998.. Food and chemical toxicology.

[14] A. Kedrov., Hellawell, A., Klosin, A., 2010. Structure.

[15] J. Laurens., Bekker, L., 2001. of Chromatography B:

[16] P. Steenkamp., Harding, N., 2006. in alleged herbal poisonings. science international.

[17] Liang-Yu Chen, Anren Hu and Chih-Jui Chang. Molecules. 2013. 18, 2018-2028

[18] Chen, L.-Y., Hu, A., Chang, C.-J., 2013. The degradation mechanism of toxic atractyloside in herbal medicines by decoction. Molecules (Basel, Switzerland) 18, 2018-28. doi:10.3390/molecules 18022018

[19] Obatomi, D.K.; Bach, P.H. Biochemistry and toxicology of the diterpenoid glycoside atractyloside. Food Chem. Toxicol. 1998, 36, 335-346.

[20] Steenkamp, P.A.; Harding, N.M.; van Heerden, F.R.; van Wyk, B.E. Determination of atractyloside in Callilepis laureola using solid-phase extraction and liquid chromatography-atmospheric pressure ionisation mass spectrometry. J. Chromatogr. A 2004, 1058, 153-162.

[21] H.C. Chien,; Chiu,C.-M. ; Hu, A.; Wu H-C.; Ye, S-P.; Ho, K.-C; and Chen, L.Y. J. Biochemistry (2012) 53: 459-465

[22] Fassina G, Veronese G. Analysis of extracts of Atractylis gummifera. IV. Chromatographic studies of the pigments of the rhizome. Boll Soc Ital Biol Sper. 1961; 37: 518-520.

[23] Buscemi, S.; Rosselli, S.; Bruno, M.; Vivona, N.; Piozzi, F. Photoinduced functionalization of diterpenes: Transformation of the C20 methyl of atractyligenin into a carbomethoxymethyl or carbamoylmethyl group. J. Photochem. Photobiol. A 2003, 155, 145149. 26.

[24] Franje, C.A.; Chang, S.K.; Shyu, C.L.; Davis, J.L.; Lee, Y.W.; Lee, R.J.; Chang, C.C.; Chou, C.C. Differential heat stability of amphenicols characterized by structural degradation, mass spectrometry and antimicrobial activity. J. Pharm. Biomed. Anal. 2010, 53, 869-877. 27.

[25] Toh, D.F.; New, L.S.; Koh, H.L.; Chan, E.C. Ultra-high performance liquid chromatography/ time-of-flight mass spectrometry (UHPLC/TOFMS) for time-dependent profiling of raw and steamed Panax notoginseng. J. Pharm. Biomed. Anal. 2010, 52, 43-50.

[26] Chu, C.; Ho, K.; Hu, A.; Chiu, C.; Wu, H.; Ye, S.; Chen, L. Bot. Stud. 2012, 53, 459-465.

[27] Chen, L.-Y., C.-X. Chen, and C.-K. Lee., 2011.. MC-Transaction on Biotechnology.

[28] Jiang, Y., David, B., Tu, P., Barbin, Y., 2010.-a review. Analytica chimica acta.

[29] Chau, C.F.; Wu, S.-H. Trends Food Sci. Technol. 2006, 17, 313-323.

[30] Jean-Frédéric Sanchez, Brice Kauffmann, Axelle Grélard, Corinne Sanchez b, Véronique Trézéguet ,Ivan Huc . Bioorganic \& Medicinal Chemistry Letters 22 (2012) 2973-2975

[31] Hodge, A and Sterner B. Toxicity Classes .In Canada Center for occupational health and safety, 2005. 